\title{
Optimization of dose calculation of modified magnetite during sorption purification of water from copper ions to create environmentally friendly technology
}

\author{
Inna Trus ${ }^{1}$, Mukola Gomelya ${ }^{1}$, Evhen Chuprinov $^{2}$, and Tetiana Pylypenko ${ }^{1}$ \\ ${ }^{1}$ National Technical University of Ukraine «Igor Sikorsky Kyiv Polytechnic Institute», 37 Peremogy Ave., Kyiv, 03056, Ukraine \\ ${ }^{2}$ State University of Economics and Technology, 5 Stepana Tilhy Str., Kryvyi Rih, 50006, Ukraine
}

\begin{abstract}
Due to the growth of man-caused pollution, there is a need to use modern methods of water purification. It is advisable to use sorption methods for the extraction of heavy metals, which are considered to be particularly dangerous. It is established that sorbents based on magnetite are quite effective in the extraction of copper ions. It is shown that the sorption capacity of magnetite-based sorbents towards copper ions depends on the ratio of concentrations of $\mathrm{Fe}^{2+}$ and $\mathrm{Fe}^{3+}$ ions in the reaction mixture, and increases with increasing this indicator from $1 / 2$ to 2 . The sorption capacity of the sorbent towards copper ions increases by 4.4 times. It is shown that the efficiency of copper ions removal onto magnetite increases for sorbent modified with sodium sulfide. The proposed scheme provides the possibility of sorption treatment of large volumes of water from copper ions to the norms for the discharge of wastewater into fishery reservoirs. Post-productional magnetite is dehydrated and supplied to metallurgical enterprises for processing. The developed technology of water purification from copper ions is environmentally safe and energy efficient.
\end{abstract}

\section{Introduction}

The end of the XX and the beginning of the XXI century were marked by both scientific and technical achievements and a significant deterioration of the environment as a result of massive pollution. The state of the hydrosphere is becoming more and more worrying every year.

The problem of protection of hydro-ecosystems from pollution in Ukraine is especially acute, where, despite the decline in industrial production, the intensity of natural water pollution is growing [1-4].

The problem of pollution of water bodies with pollutants of various natures is now arising in many countries around the world. Heavy metals come to natural sources with effluents from various enterprises (galvanic, instrument-making and chemical industries, mining and processing plants and thermal power plants). A significant increase in the allowable discharges of heavy metal ions is observed in the discharges of nuclear power plants [5-9].

When discharging untreated or insufficiently treated galvanic effluents into rivers, lakes and other surface water bodies that contain a significant amount of heavy metals in their composition, enormous damage is caused to the environment: significant damage is caused to aquatic organisms and the ability of reservoirs to self-clean [1017]. Some heavy metals are incapable of decomposition and accumulate in food chains.

Greening of processes for the introduction of lowwaste methods is one of the key trends in the development of modern technologies. They are aimed at obtaining new highly selective, multifunctional materials to ensure environmental safety. Despite the presence of a large number of already known methods and techniques of synthesis, most of them occur with the participation of toxic reagents and are ineffective and dangerous to the environment. Traditional methods allow obtaining materials with the limited functional properties. This problem is becoming more important not only for Ukraine, but for the whole world [18-21].

The latest alternative types of multifunctional materials include nanomaterials and composite materials based on them, namely sorbents for water purification from organic impurities and heavy metals [22, 23].

Therefore, the development of methods for obtaining highly efficient sorbents, in order to ensure the rational use of natural resources in the application of new technologies, the progressive organization of low-waste and non-waste industries is extremely important.

Since heavy metals are priority contaminants, there is a need for modern methods that can provide high efficiency of purification from heavy metal ions [24-27].

When choosing a method of water purification, data on the volume of effluents, composition and content of impurities in them and technical and economic analysis were used $[28,29]$. 


\section{Analysis of previous studies}

Extraction of copper ions from water with a high degree of purification, as well as the water purification from other heavy metals is quite difficult. Known methods of water purification from heavy metal ions are accompanied by the formation of toxic sludge, which is difficult to dispose of, or liquid waste, the processing of which requires significant costs. In addition, most of the known methods of water purification from heavy metal ions do not possess the necessary extraction efficiency. It is known that in fishery reservoirs, the maximum allowable concentration of copper ions reaches $1 \mu \mathrm{g} / \mathrm{dm}^{3}$. Therefore, even when discharging relatively clean wastewater from power plants, where the content of copper ions reaches $\sim 50$ $\mu \mathrm{g} / \mathrm{dm}^{3}$, there is a risk of exceeding the maximum concentration limit in such reservoirs. However, most of the known methods of water purification from copper ions do not provide the required efficiency of water purification. The problem is complicated by large volumes of wastewater containing copper ions [30, 31].

Electrochemical methods are characterized as effective and advanced water purification technologies. Installations are quite compact and high-performative, while control and operation processes are simply automated. Electrochemical methods allow one to extract valuable components from effluents with a relatively simple automated technological scheme of treatment, often without the use of chemical reagents. The main disadvantage of these methods is the high cost of electricity [32-42].

Among the advantages of baromembrane methods are: low energy consumption, simplicity of construction of devices and installations, as well as their small size. The devices are easy to operate and consumed energy is mainly spent on creating high pressure over the solution. Disadvantages include the occurrence of the phenomenon of concentration polarization, which leads to a deterioration in the characteristics of membrane devices and the need for preliminary preparation of solutions [4353].

Purification methods based on ion exchange using natural and synthetic materials are widely used. However, the main disadvantage of the ion exchange method is the need to supply to ion exchange units wastewater, pretreated from suspended solids, cyanides, iron ions, petroleum products and other organic substances [54-57].

Sorption methods of wastewater treatment are highly efficient and are among the most environmentally friendly methods. The main criterion when choosing a material for wastewater treatment is its sorption properties, porous structure and efficiency. Therefore, the presented work is aimed at developing and improving methods of sorption purification of water from the heavy metals [58-62].

\section{Results of the study}

The aim of the work was to study the processes of copper ions extraction from water using sorbents based on magnetite, in order to determine the optimal conditions for modification of sorbents to achieve effective purification of water from copper ions to the maximum allowable concentration.

It is known that magnetite-based sorbents provide efficient extraction of heavy metal ions from water. They are quite effective in removing heavy metal ions in the presence of hardness ions [63]. Typically, magnetite obtained at a ratio of iron (II) and iron (III) ions in the reaction mixture of $1: 2$ is used, although it is known that with increasing iron (II) content, magnetite has a more amorphous structure, which should affect its sorption capacity. Therefore, magnetite was used in this work, at a ratio of $\mathrm{Fe}$ (II) / Fe (III) $1: 2 ; 1: 1$ and $2: 1$. To increase the sorption capacity of magnetite, sodium sulfide was added at a concentration of 1 and $2 \%$.

When purifying water from copper ions when using sorbents based on magnetite, the sorption capacity of magnetite $(\mathrm{K}=1: 1)$ for copper is almost $10 \%$ greater than when using magnetite obtained at $\mathrm{K}=1: 2$.

The sorption capacity of magnetite increases with increasing ratio $\mathrm{K}=\left[\mathrm{Fe}^{2+}\right] /\left[\mathrm{Fe}^{3+}\right]$ in the range $1: 2 ; 1: 1$ and $2: 1$. Thus, at $\mathrm{K}=1: 2$ the sorption capacity of magnetite did not exceed $100 \mathrm{mg} / \mathrm{g}$ in the entire range of selected concentrations.

At $\mathrm{K}=1: 1$, the sorption capacity of magnetite reached $108 \mathrm{mg} / \mathrm{g}$ for sorption from distilled water and $134 \mathrm{mg} / \mathrm{g}$ for sorption from tap water.

At $\mathrm{K}=2$, the sorption capacity of magnetite in both distilled and tap water exceeded $200 \mathrm{mg} / \mathrm{g}$. This suggests that with increasing ratio $\mathrm{K}$, magnetite has more amorphous structure, which causes an increase in its sorption capacity. In addition, it is obvious from the above data that calcium and magnesium ions are practically not sorbed on magnetite and therefore do not affect the sorption of copper ions. This is very important because with such properties of the sorbent it can be used to extract heavy metal ions from both natural and wastewater containing hardness ions. When using magnetite, only heavy metal ions are sorbed without removing hardness ions. When using cation exchange resins, hardness ions and heavy metal ions are sorbed together, and the ratio of the capacity of the cation exchange resin to hardness ions and heavy metal ions is close to the ratio of the concentrations of these cations in solution. And if we take into account that the concentrations of hardness ions in water are often tens of times higher than the concentrations of heavy metal ions, then it becomes clear that the use of ion exchange resins is appropriate only with deep softening of water. This approach is inappropriate when it comes to wastewater treatment.

To implement the method of sorption water purification, it is necessary to have detailed relationships between the main parameters of the process in optimal conditions. Therefore, the regression equations were calculated to illustrate the dependence of the sorption capacity of magnetite on the ratio of $\mathrm{Fe}$ (II) / Fe (III) and the equilibrium concentration of copper ions.

The calculation was based on a complete factor plan (CFP) type $2^{2}$. The plan-matrix CFP $2^{2}$ and the results of the experiment of the sorption capacity of magnetite from the ratio of $\mathrm{Fe}$ (II) / $\mathrm{Fe}$ (III) and the equilibrium concentration of copper ions in distilled water are shown in table 1 . 
Table 1. Plan-matrix CFP $2^{2}$ and the results of the study of the extraction of sorption extraction of copper ions from distilled water.

\begin{tabular}{|c|c|c|c|c|}
\hline \multicolumn{2}{|c|}{ Planning matrix } & $\begin{array}{c}\text { Natural value of } \\
\text { factors }\end{array}$ & $\begin{array}{c}\text { Value of } \\
\text { parameters }\end{array}$ \\
\hline $\mathbf{x}_{\mathbf{1}}$ & $\mathbf{x}_{\mathbf{2}}$ & $\mathbf{C e}, \mathbf{m g} / \mathbf{m}^{\mathbf{3}}$ & $\mathbf{K}$ & $\mathbf{a}, \mathbf{m g} / \mathbf{g}$ \\
\hline-1 & -1 & 2.0 & 0.5 & 34.23 \\
\hline+1 & -1 & 104.0 & 0.5 & 66.89 \\
\hline-1 & +1 & 2.0 & 2.0 & 23.98 \\
\hline+1 & +1 & 104.0 & 2.0 & 210.00 \\
\hline
\end{tabular}

As a result of appropriate calculations and after checking the conformity of the study results, assessing the significance of the obtained coefficients and checking the regression equation for adequacy, the unknown dependence is as follows:

$$
y=83.775+54.670 \cdot X_{1}+33.215 \cdot X_{2}+38.340 \cdot X_{I} \cdot X_{2}(1)
$$

After replacing the code values in the obtained equation with natural ones,

$$
\begin{aligned}
& X_{1}=\left(C_{e}-53\right) / 51 \\
& X_{2}=(K-1.25) / 0.75
\end{aligned}
$$

we obtained the following regression equation:

$$
Y=38.009-0.181 \cdot C_{e}-8.808 \cdot K+1.024 \cdot C_{e} \cdot K
$$

The obtained dependence is presented in Fig. 1 in the form of a plane on which lies the solution of the given equation. The figure shows the dependence of the sorption capacity of magnetite on the ratio of Fe (II) / Fe (III) and the initial concentration of copper ions in distilled water.

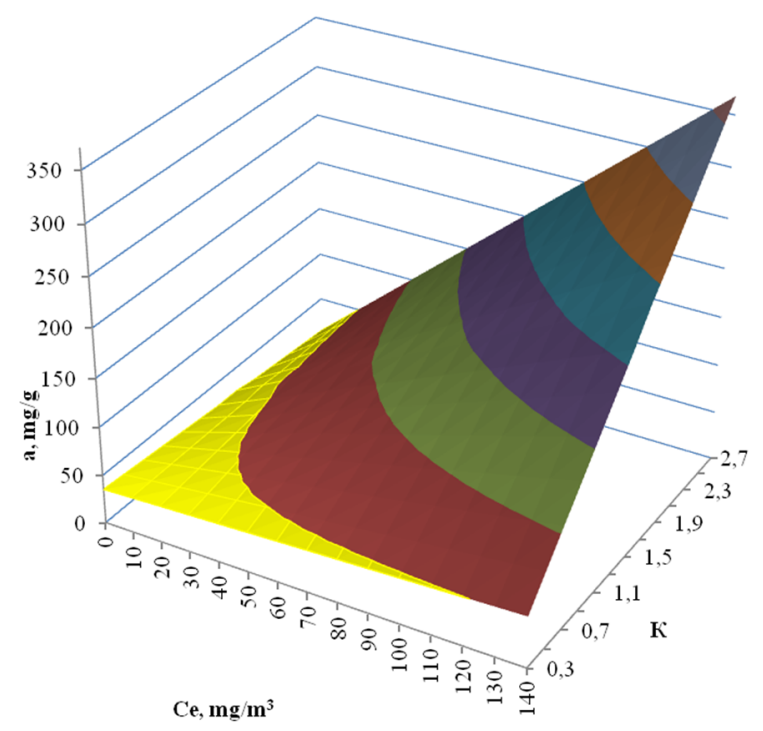

$=350-370=300-350=250-300=200-250 \quad \square 150-200=100-150=50-100=0-50$

Fig. 1. Graphical representation of the results of CFP type $2^{2}$ dependence of the sorption capacity of magnetite on the ratio of $\mathrm{Fe}$ (II) / Fe (III) and the equilibrium concentration of copper ions in distilled water.

The analysis of the presented graphs shows that the experimental points that were used in the calculation of the regression equation are on the constructed plane of solutions, which indicates the adequacy of the equation used. Using the data of the regression equation, it is quite easy to calculate the optimal ratio of Fe (II) / Fe (III) for effective purification of the solution from copper ions.

If we look at Fig. 1, we can say that in this case the mechanism of activated adsorption takes place. The reason for this is that the copper ions are included in the crystal lattice of magnetite. At low concentrations of copper at $\mathrm{K}=1: 1$ and 2: 1 , almost complete extraction of copper is observed, which can be explained by this mechanism of sorption. In this case, heavy metal ions are practically not desorbed from magnetite without acid treatment and destruction of the structure of the sorbent.

Regression equations were calculated for the dependence of the sorption capacity of magnetite on the ratio of $\mathrm{Fe}$ (II) / Fe (III) and the equilibrium concentration of copper ions in tap water.

Plan-matrix CFP $2^{2}$ and the results of the experiment of sorption capacity of magnetite from the ratio of $\mathrm{Fe}$ (II) / Fe (III) and the equilibrium concentration of copper ions in tap water are shown in table 2.

Table 2. Plan-matrix CFP $2^{2}$ and the results of the study of sorption extraction of copper from tap water.

\begin{tabular}{|c|c|c|c|c|}
\hline \multicolumn{2}{|c|}{ Planning matrix } & \multicolumn{2}{|c|}{$\begin{array}{c}\text { Natural value of } \\
\text { factors }\end{array}$} & $\begin{array}{c}\text { Value of } \\
\text { parameters }\end{array}$ \\
\hline $\mathbf{x}_{\mathbf{1}}$ & $\mathbf{\mathbf { x } _ { 2 }}$ & $\mathbf{C e}, \mathbf{m g} / \mathbf{m}^{\mathbf{3}}$ & $\mathbf{K}$ & $\mathbf{a}, \mathbf{m g} / \mathbf{g}$ \\
\hline-1 & -1 & 2.0 & 0.5 & 44.1 \\
\hline+1 & -1 & 104.0 & 0.5 & 70.0 \\
\hline-1 & +1 & 2.0 & 2.0 & 36.0 \\
\hline+1 & +1 & 104.0 & 2.0 & 219.0 \\
\hline
\end{tabular}

As a result of appropriate calculations and after checking the conformity of the study results, assessing the significance of the obtained coefficients and checking the regression equation for adequacy, the unknown dependence is as follows:

$Y=92,275+52,225 \cdot X_{1}+35,225 \cdot X_{2}+39,275 \cdot X_{1} \cdot X_{2}$

After replacing the code values in the obtained equation with natural ones,

$$
\begin{aligned}
& X_{1}=\left(C_{e}-53\right) / 51 \\
& X_{2}=(K-1.25) / 0.75
\end{aligned}
$$

we obtained the following regression equation:

$$
Y=47.319-0.2595 \cdot C_{e}-7.4536 \cdot K+1.0268 \cdot C_{e} \cdot K
$$

The obtained dependence is presented in Fig. 2 in the form of a plane on which lies the solution of the given equation. The figure shows the dependence of the sorption capacity of magnetite on the ratio of $\mathrm{Fe}$ (II) / Fe (III) and the equilibrium concentration of copper ions in tap water.

Increasing the sorption capacity of magnetite towards copper with increasing the ratio of $\mathrm{K}$ from $1: 2$ to $2: 1$ in addition to the positive value has significant disadvantages. First of all, magnetite obtained at $\mathrm{K}=1: 2$ has the highest magnetic characteristics, which simplifies its separation from water, has the highest sludge density and the highest chemical resistance, because it has a 
crystalline structure. As the value of $\mathrm{K}$ increases, the contribution of amorphous elements to magnetite increases, which impairs its magnetic properties, reduces chemical resistance and leads to an increase in the volume of sediment due to a decrease in its density. Therefore, to increase the sorption capacity of magnetite obtained at a ratio of $\mathrm{K}=1: 2$ in the process of its synthesis was modified with sodium sulfide. These substance, which is partially included in the structure of magnetite, contain functional groups $\mathrm{Me}=\mathrm{S}$, which are able to form complex bonds with heavy metal ions (with d-metals), do not interact with hardness ions and are able to increase the sorption capacity of magnetite. The results shown in Fig. 3 confirm this assumption. Modified forms of magnetite are dominated by unmodified magnetite, when copper ions are sorbed from tap water. Similar results are observed in the extraction of copper from distilled water. The equilibrium adsorption increases during the transition from unmodified magnetite to magnetite modified with sodium sulfide. Sodium sulfide provides the value of the limiting adsorption at the range of $332-388 \mathrm{mg} / \mathrm{g}$, and is also a very affordable and cheap reagent and quite resistant to hydrolysis in alkali solutions.

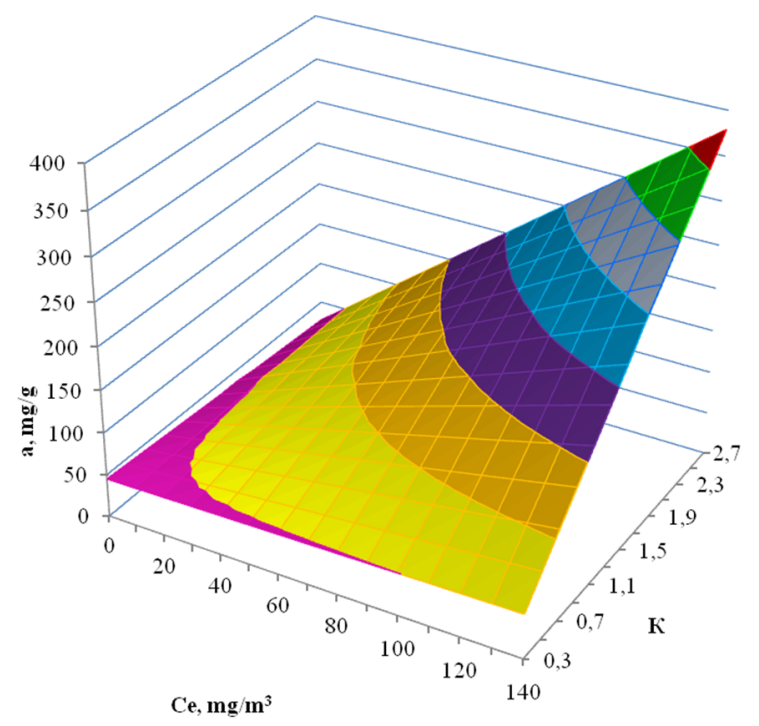

$\square 350-400 \square 300-350 \square 250-300 \square 200-250 \square 150-200 \square 100-150 \square 50-100 \square 0-50$

Fig. 2. Graphical representation of the results of CFP type $2^{2}$ sorption capacity of magnetite from the ratio of Fe (II) / Fe (III) and the equilibrium concentration of copper ions in tap water.

Regression equations for the dependence of the sorption capacity of magnetite on the equilibrium concentration of copper ions in tap water and the concentration of sodium sulfide were calculated.

Plan-matrix CFP $2^{2}$ and the results of the experiment of the sorption capacity of magnetite from the equilibrium concentration of copper ions in tap water and the concentration of sodium sulfide are shown in table 3 .

As a result of appropriate calculations and after checking the conformity of the study results, assessing the significance of the obtained coefficients and checking the regression equation for adequacy, the unknown dependence is as follows:
$\mathrm{Y}=164.5525+98.6475 \cdot \mathrm{X}_{1}+24.9475 \cdot \mathrm{X}_{2}+43.852 \cdot \mathrm{X}_{1} \cdot \mathrm{X}_{2}$ (9)

Table 3. Plan-matrix CFP $2^{2}$ and the results of the study of the extraction of copper from tap water using magnetite modified with sodium sulfide.

\begin{tabular}{|c|c|c|c|c|}
\hline \multicolumn{2}{|c|}{ Planning matrix } & $\begin{array}{c}\text { Natural value of } \\
\text { factors }\end{array}$ & $\begin{array}{c}\text { Value of } \\
\text { parameters }\end{array}$ \\
\hline $\mathbf{x}_{\mathbf{1}}$ & $\mathbf{x}_{\mathbf{2}}$ & $\mathbf{C e}, \mathbf{m g} / \mathbf{m}^{\mathbf{3}}$ & $\mathbf{C ~ ( \mathbf { N a } _ { 2 } \mathbf { S } )}$ & $\mathbf{a}, \mathbf{m g} / \mathbf{g}$ \\
\hline-1 & -1 & 1.0 & 1.0 & 84.81 \\
\hline+1 & -1 & 250.0 & 1.0 & 194.4 \\
\hline-1 & +1 & 1.0 & 2.0 & 47.0 \\
\hline+1 & +1 & 250. & 2.0 & 332.0 \\
\hline
\end{tabular}

After replacing the code values in the obtained equation with natural ones,

$$
\begin{aligned}
& X_{1}=\left(C_{e}-125.5\right) / 124.5 \\
& X_{2}=\left(\mathrm{C}\left(\mathrm{Na}_{2} \mathrm{~S}\right)-1.5\right) / 0.5
\end{aligned}
$$

we obtained the following regression equation:

$$
\begin{aligned}
& Y=122.884-0.26434 \cdot C_{e}-38.5145 \cdot C\left(N a_{2} S\right)+ \\
& 0.70446 \cdot C_{e} \cdot C\left(N a_{2} S\right)
\end{aligned}
$$

The obtained dependence is presented in Fig. 3 in the form of a plane on which lies the solution of the given equation. The figure shows the dependence of the sorption capacity of magnetite on the equilibrium concentration of copper ions in tap water and the concentration of sodium sulfide used to modify the sorbent.

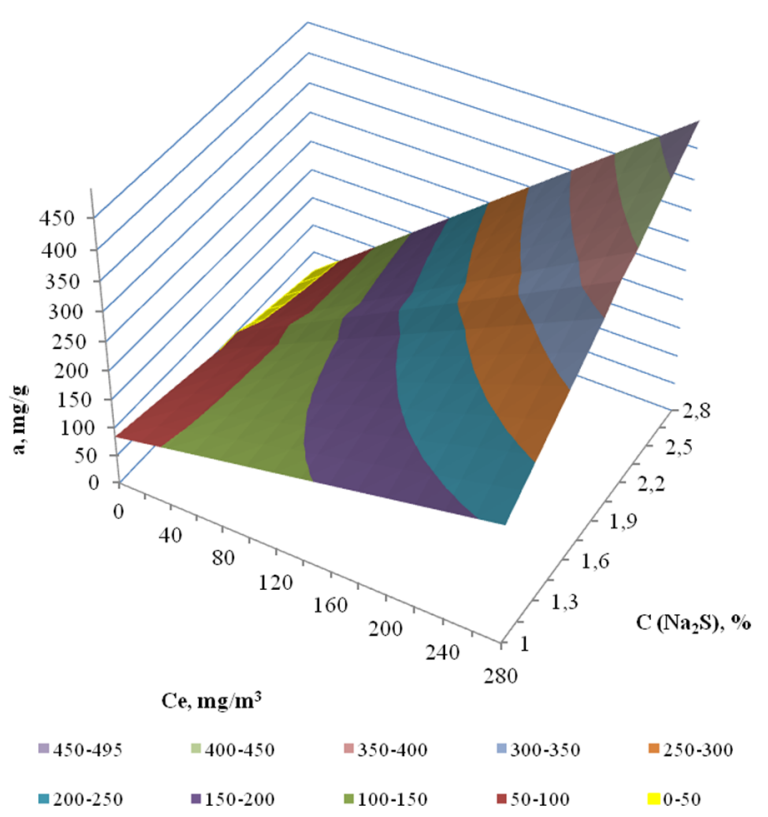

Fig. 3. Graphical representation of the results of CFP type $2^{2}$ sorption capacity of magnetite from the equilibrium concentration of copper ions in tap water and the concentration of sodium sulfide used to modify the sorbent.

The research was conducted to determine the effectiveness of the developed sorbents depending on the ratio of the amount of sorbent and the volume of the solution. It was taken into account that the main problem is the extraction of copper ions from dilute solutions. Therefore, sorption was performed at doses of magnetite 
500-10000 mg/dm ${ }^{3}$. When sorbing copper from solutions with copper concentrations of 10 and $50 \mathrm{mg} / \mathrm{dm}^{3}$, the sorption capacity of the sorbent increases with increasing dose of adsorbent. Higher values of adsorption were observed for magnetite at $\mathrm{K}=2$. Sorption increases during the transition from unmodified magnetite to magnetite modified with sodium sulfide. In the case of using magnetite modified with sodium sulfide, the sorption capacity only slightly depends on the ratio of $\mathrm{K}$.

Modification of magnetite with sodium sulfide significantly affects the equilibrium concentrations of copper in purified water. When using unmodified magnetite at $\mathrm{K}=1 / 2$, the equilibrium concentrations of copper reach values of $2.0-6.7 \mathrm{mg} / \mathrm{dm}^{3}$ and only at a dose of magnetite $10 \mathrm{~g} / \mathrm{dm}^{3}$ the equilibrium concentration decreased to $0.55 \mathrm{mg} / \mathrm{dm}^{3}$. At a ratio of $\mathrm{K}=2$ at doses of magnetite $2.5-10.0 \mathrm{~g} / \mathrm{dm}^{3}$ at an initial copper concentration of $10 \mathrm{mg} / \mathrm{dm}^{3}$, the equilibrium concentrations were in the range of $0.00-0.75 \mathrm{mg} / \mathrm{dm}^{3}$. But at lower doses of magnetite, they still increased to $2-5 \mathrm{mg} / \mathrm{dm}^{3}$. When using magnetite modified $\mathrm{Na}_{2} \mathrm{~S}$ at $\mathrm{K}$ $=1 / 2$ equilibrium concentrations of copper at an initial concentration of $10 \mathrm{mg} / \mathrm{dm}^{3}$ decreased to $0.08-0.28 \mathrm{mg} / \mathrm{dm}^{3}$ at all used doses of magnetite, and at $\mathrm{K}=2$ they were generally at the level of $0.0-0.1 \mathrm{mg} / \mathrm{dm}^{3}$. Even at an initial copper concentration of $50 \mathrm{mg} / \mathrm{dm}^{3}$ using modified magnetite $(\mathrm{K}=2)$ at doses from 1.25 to $10 \mathrm{mg} / \mathrm{dm}^{3}$, the equilibrium concentrations were at the level of $0.00-0.12 \mathrm{mg} / \mathrm{dm}^{3}$.

\section{Economic justification}

In this case, we can say that modified with sodium sulfide magnetite is a fairly affordable synthetic inorganic sorbent with high efficiency for copper ions.

Given the high quality requirements for water purification from heavy metal ions, especially when discharging them into fishery reservoirs or when preparing drinking water, it was interesting to determine the minimum concentrations that can be achieved when using magnetite-based sorbents. When using magnetite modified with sodium sulfide, the concentration of copper was reduced to $5.44 \mu \mathrm{g} / \mathrm{dm}^{3}$ at $\mathrm{K}=1: 2$ (table 4,5$)$.

Table 4. Dependence of the efficiency of extraction of copper ions from tap water on the ratio $\left[\mathrm{Fe}^{2+} / \mathrm{Fe}^{3+}\right]$ in magnetite, without modification with sodium sulfide.

\begin{tabular}{|c|c|c|c|c|}
\hline \multirow[b]{2}{*}{$\begin{array}{l}\mathrm{Fe}^{2+} / \\
\mathrm{Fe}^{3+}\end{array}$} & \multicolumn{2}{|c|}{$\mathrm{C} \mathrm{Cu}^{2+}, \mathrm{mg} / \mathrm{dm}^{3}$} & \multirow{2}{*}{$\underset{\mathrm{mg} / \mathrm{g}}{\mathrm{a}}$} & \multirow{2}{*}{$\begin{array}{c}\text { Degree } \\
\text { of } \\
\text { extractio } \\
n\end{array}$} \\
\hline & initial & $\underset{\mathrm{m}}{\text { Equilibriu }}$ & & \\
\hline $1: 2$ & 10.00 & 0.7500 & 6.3000 & 92.50 \\
\hline $1: 1$ & 10.00 & 0.1500 & 7.3888 & 98.50 \\
\hline $2: 1$ & 2.00 & 0.0166 & 1.4875 & 99.17 \\
\hline
\end{tabular}

When using sulfide-modified magnetite obtained at $\mathrm{K}=2$, and the copper concentration was reduced to $1.2 \mu \mathrm{g} / \mathrm{dm}^{3}$.

Waste should be disposed of as part of building materials. Dehydrated waste of spent magnetite can be used as a thermal additive in the manufacturing of various heat-resistant materials.
Table 5. Dependence of the efficiency of extraction of copper ions from tap water on the ratio $\left[\mathrm{Fe}^{2+} / \mathrm{Fe}^{3+}\right]$ in magnetite when modified with sodium sulfide

\begin{tabular}{|c|c|c|c|c|c|}
\hline \multirow[b]{2}{*}{$\begin{array}{c}\mathrm{Fe}^{2+} \\
/ \\
\mathrm{Fe}^{3+}\end{array}$} & \multirow[b]{2}{*}{$\begin{array}{c}\mathrm{Na}_{2} \mathrm{~S} \\
, \%\end{array}$} & \multicolumn{2}{|c|}{$\mathrm{C} \mathrm{Cu}^{2+}, \mathrm{mg} / \mathrm{dm}^{3}$} & \multirow{2}{*}{$\begin{array}{c}\mathrm{a}, \\
\mathrm{mg} / \mathrm{g}\end{array}$} & \multirow{2}{*}{$\begin{array}{c}\text { Degree } \\
\text { of } \\
\text { extractio } \\
n\end{array}$} \\
\hline & & Initial & $\begin{array}{c}\text { Equilibri } \\
\text { um }\end{array}$ & & \\
\hline $1: 2$ & 1 & 1.63 & 0.00540 & 1.0292 & 99.67 \\
\hline $1: 2$ & 2 & 1.63 & 0.04688 & 0.9960 & 97.12 \\
\hline $1: 1$ & 2 & 10.0 & 0.05600 & 7.4580 & 99.44 \\
\hline $2: 1$ & 2 & 2.0 & 0.00120 & 1.4991 & 99.94 \\
\hline
\end{tabular}

\section{Conclusions}

The application of modified sorbent based on magnetite for water purification from copper ions is the promising direction of sorption technologies, which allows to increase the efficiency of the process. When using modified sorbents based on magnetite, it is possible to

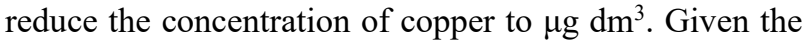
high capacity of the sorbent on copper ions, it will be possible to implement low-waste technology of water purification from heavy metals during its use.

The use of modified magnetite is a cost-effective way to purify water from heavy metals. The spent sorbent is utilized at the metallurgical enterprises.

Based on the complete factor plan, a regression equation is obtained, it has a linear character, which allows to optimize the calculation of the magnetite dose for efficient extraction of copper ions from aqueous solutions.

Given the constant increase in the concentration of hazardous pollutants in water bodies, the next step will be the development and implementation of methods for extracting a mixture of heavy metals from water and developing a mathematical model of the process to find optimal desalination parameters.

The work was supported by National Research Fund of Ukraine, grant № 144/01.2020

\section{References}

1. V. Buzylo, A. Pavlychenko, T. Savelieva, O. Borysovska, Paper presented at the E3S Web of Conferences,

60,

(2018).doi:10.1051/e3sconf/20186000013

2. I. Trus, N. Gomelya, V. Halysh, I. Radovenchyk, O. Stepova, O. Levytska, Eastern-European Journal of Enterprise Technologies, 3/6 (105),21-27. (2020). https://doi.org/10.15587/1729-4061.2020.206443

3. V. I. Hryniuk, L. M. Arkhypova, Naukovyi Visnyk Natsionalnoho Hirnychoho Universytetu, 3, 125-133 (2018)

4. M. Korchemlyuk, L. Arkhipova, R. L. Kravchynskyi, J. D. Mykhailyuk, Naukovyi Visnyk Natsionalnoho Hirnychoho Universytetu, 1, 125-131 (2019)

5. S. Muhammad, M. Tahir Shah, and S. Khan, Food and Chemical Toxicology, 48 (10), 2855-2864, (2010) 
6. S. Venkatramanan, S. Y. Chung, T. H. Kim, M. V. Prasanna, and S. Y. Hamm, Water Quality, Exposure and Health, 7 (2), 219-225, (2015)

7. A. K. Krishna, M. Satyanarayanan, and P. K. Govil, Journal of Hazardous Materials, 167 (1-3), 366-373, (2009)

8. S. Rapant and K. Krěmová, Environmental Geochemistry and Health, 29 (2), 131-141, (2007)

9. R. Dixit, D. Wasiullah, Malaviya, K. Pandiyan, U.B. Singh, A., Sahu, R., Shukla, (...), D. Paul, Sustainability (Switzerland), 7 (2), 2189-2212 (2015). doi: 10.3390/su7022189.

10. L.A.Malik, A.Bashir, A.Qureashi, A. H. Pandith, Environmental Chemistry Letters, 17(4), 1495-1521 (2019)

11. A. Demirak, F. Yilmaz, A. Levent Tuna, and N. Ozdemir, Chemosphere, 63 (9), 1451-1458 (2006)

12. K. H.Vardhan, P. S.Kumar, R. C. Panda, Journal of Molecular Liquids, 290., 111197 (2019). doi: 10.1016/j.molliq.2019.111197

13. P. Chanpiwat, S. Sthiannopkao, and K.-W. Kim, Microchemical Journal, 95 (2), 326-332, (2010)

14. C. Karthik, P. I. Arulselvi, Geomicrobiology Journal, 34(5), 434-442

(2017). doi:10.1080/01490451.2016.1219429

15. B. E. Igiri, S. I. R. Okoduwa, G. O. Idoko, E. P. Akabuogu, A. O. Adeyi, I. K. Ejiogu, Journal of Toxicology, $2018 \quad$ (9), $2568038 \quad$ (2018). doi:10.1155/2018/2568038

16. H. M. Hussein, Indian Journal of Forensic Medicine and Toxicology, 14(2), 931-936 (2020)

17. A.Rizvi, M. S. Khan, Chemosphere, 185, 942-952 (2017). doi:10.1016/j.chemosphere.2017.07.088

18. I. Trus, I. Radovenchyk, V. Halysh, M. Skiba, I. Vasylenko, V. Vorobyova, O. Hlushko, L. Sirenko, Journal of Ecological Engineering, 20(8), 107-113 (2019) doi.org/10.12911/22998993/110767

19. S. Siddiquee, K. Rovina, and S. A. Azad, Journal of Microbial and Biochemical Technology, 07 (06), 384-393 (2015)

20. D. Lakherwal, International Journal of Environmental Research Development, 4, 41-48 (2014)

21. M. O. Fashola, V. M. Ngole-Jeme, O. O. Babalola, International Journal of Environmental Research and Public Health, 13 (11), 1047 (2016)

22. V. Halysh, I. Trus, A. Nikolaichuk, M. Skiba, I. Radovenchyk, I. Deykun, V. Vorobyova, I. Vasylenko, L. Sirenko, Journal of Ecological Engineering, 21(2), 131-138 (2020) doi.org/10.12911/22998993/116328

23. I. Trus, N. Gomelya, G. Trokhymenko, N. Magas, O. Hlushko, Eastern-European Journal of Enterprise Technologies, 6/10 (102), 49-54 (2019). doi.org/10.15587/1729-4061.2019.188295
24. T. O. Ajiboye, O. A. Oyewo, D. C. Onwudiwe, Chemosphere, $262 \quad$ (2021). doi:10.1016/j.chemosphere.2020.128379

25. H. Peng, J. Guo, Environmental Chemistry Letters, 18(6), 2055-2068 (2020). doi:10.1007/s10311-02001058-X

26. F. Fu, Q. Wang, Journal of Environmental Management, 92(3), 407-418 (2011). doi:10.1016/j.jenvman.2010.11.011

27. C. E. Barrera-Díaz, V. Lugo-Lugo, B. Bilyeu, Journal of Hazardous Materials, 223-224, 1-12 (2012). doi:10.1016/j.jhazmat.2012.04.054

28. M. A. Barakat, Arabian Journal of Chemistry, 4, 361377 (2011)

29. S. K. Gunatilake, Journal of Multidisciplinary Engineer-ing Science Studies, 1, 12-18 (2015)

30. M. K. Doula, A., J. Hazard. Mater, 151, 738-745 (2008)

31. E. Pehlivan, T. Altun, Journal of Hazardous Materials, 140, 1, 299-307 (2007)

32. K. Dermentzis, Journal of Hazardous Materials, 173, 647-652 (2010)

33. I. Koliehova, G. Trokhymenko, N. Magas, N. Gomelya, I. Trus, Journal of Ecological Engineering, 21(2), 29-38 doi.org/10.12911/22998993/116351

(2020)

34. X. Chen, P. Ren, T. Li, J. P. Trembly, Liu, Chemical Engineering Journal, 349, 358-367 (2018)

35. A. Tahreen, M. S. Jami, F. Ali, Journal of Water $\begin{array}{llll}\text { Process } & \text { Engineering, } & 37 & \text { (2020). }\end{array}$ doi:10.1016/j.jwpe.2020.101440

36. A. Shahedi, A. K. Darban, F. Taghipour, A. JamshidiZanjani, Current Opinion in Electrochemistry, 22, 154-169 (2020). doi:10.1016/j.coelec.2020.05.009

37. R. Zhou et al, Journal of Water Process Engineering, 37 (2020). doi:10.1016/j.jwpe.2020.101387

38. P. Krystynik, P. Masin, Z. Krusinova, P. Kluson, International Journal of Environmental Science and Technology, 16(8), 4167-4172 (2019). doi:10.1007/s13762-018-2074-3

39. F. Akbal, S. Camcidotless, Desalination, 269(1-3), 214-222 (2011). doi:10.1016/j.desal.2010.11.001

40. J. Yang, F. Liu, Y. Bu, N. Wei, S. Liu, J. Chang, ... C. Zhang, Environmental Technology and Innovation, 20 (2020). doi:10.1016/j.eti.2020.101123

41. E. Keshmirizadeh, S. Yousefi, M. K. Rofouei, Journal of Hazardous Materials, 190(1-3), 119-124 (2011). doi:10.1016/j.jhazmat.2011.03.010

42. N. S. Graça, A. M. Ribeiro, A. E. Rodrigues, Chemical Engineering Science, 197, 379-385 (2019). doi:10.1016/j.ces.2018.12.038

43. Maher Amen, Ahmad Moheb, Desalination, 352, 166-173 (2014)

44. K. Ambiado, C. Bustos, A. Schwarz, R. Bórquez, Water Science and Technology, 75(3), 705-715 (2017) 
45. B. A. M. Al-Rashdi, D. J. Johnson, N. Hilal, Desalination, $\quad 315, \quad 2-17 \quad$ (2013). doi:10.1016/j.desal.2012.05.022

46. L. Pino, E. Beltran, A. Schwarz, M. C., Ruiz, R. Borquez, Hydrometallurgy, $195 \quad$ (2020). doi:10.1016/j.hydromet.2020.105361

47. B. Vital, J. Bartacek, J. C.Ortega-Bravo, D. Jeison, Chemical Engineering Journal, 332, 85-91 (2018). doi:10.1016/j.cej.2017.09.034

48. C. -.Gherasim, P. Mikulášek, Desalination, 343, 6774 (2014). doi:10.1016/j.desal.2013.11.012

49. M. Giagnorio, S. Steffenino, L. Meucci, M. C. Zanetti, A. Tiraferri, Journal of Environmental Chemical Engineering, 6(4), 4467-4475 (2018). doi:10.1016/j.jece.2018.06.055

50. P. Choudhury, P. Mondal, S. Majumdar, S. Saha, G. C. Sahoo, Journal of Cleaner Production, 203, 511520 (2018). doi:10.1016/j.jclepro.2018.08.289

51. M. T. Hoang, T. D. Pham, D. Verheyen, M. K. Nguyen, T. T. Pham, J. Zhu, B. Van der Bruggen, Chemical Engineering Science, 228 (2020). doi:10.1016/j.ces.2020.115998

52. S. Roy, S. Majumdar, G. C. Sahoo, S. Bhowmick, A. K. Kundu, P. Mondal, Journal of Hazardous Materials, 399 (2020). doi:10.1016/j.jhazmat.2020.122841

53. I.M. Trus, M.D. Gomelya, I.M. Makarenko, A.S. Khomenlo, G.G. Trokhymenko, Naukovyi Visnyk Natsionalnogo Hirnychogo Universytety, 4., 117123 (2020) doi.org/10.33271/nvngu/2020-4/117

54. A. Bashir, L. A. Malik, S. Ahad, T. Manzoor, M. A. Bhat, G. N. Dar, A. H. Pandith, Environmental Chemistry Letters, 17(2), 729-754 (2019). doi:10.1007/s10311-018-00828-y

55. D. Chen, W. Shen, S. Wu, C. Chen, X. Luo, L. Guo, Nanoscale, 8(13), 7172-7179 (2016). doi:10.1039/c6nr00695g

56. Y. Ren, Y. Han, X. Lei, C. Lu, J. Liu, G. Zhang,. . . Q. Zhang, Physicochemical and Engineering Aspects, 604 (2020). doi:10.1016/j.colsurfa.2020.125279

57. A.Dạbrowski, Z.Hubicki, P.Podkościelny, E.Robens, Chemosphere, 56(2), 91-106 (2004)

58. N. Feng, X. Guo, S. Liang, Transactions of Nonferrous Metals Society of China, 19, 5, 13651370 (2009)

59. Z. Anfar, H. Ait Ahsaine, M. Zbair, A. Amedlous, A. Ait El Fakir, A. Jada, N. El Alem, Critical Reviews in Environmental Science and Technology, 50(10), 1043-1084 doi:10.1080/10643389.2019.1642835

60. D. Roy, S. Neogi, S. De, Journal of Hazardous Materials, 403 doi:10.1016/j.jhazmat.2020.123624

61. A. Bashir, T. Manzoor, L. A. Malik, A. Qureashi, A. H. Pandith, ACS Omega, 5(10), 4853-4867 (2020). doi:10.1021/acsomega.9b03607
62. C. Duan, T. Ma, J. Wang, Y. Zhou, Journal of Water Process Engineering, $37 \quad$ (2020). doi:10.1016/j.jwpe.2020.101339

63. Trokhymenko G., Gomelya M., Chemistry and Chemical Technology, 11 (3), 372-377 (2017). https://doi.org/10.23939/chcht11.03.372 